\title{
Factors Influencing Depression in Married Immigrant Women
}

\author{
Tae Kyung Kim ${ }^{1}$, Hye Jin $\mathrm{Kim}^{2}$ and Eun Kwang Yoo ${ }^{3}$ \\ ${ }^{1}$ Professor, Department of Nursing, DongEui Institute of Technology, Pusan 614- \\ 715, Korea \\ ${ }^{2}$ Professor, Department of Nursing, Kyungbok University, Pocheon 487-717, \\ Korea \\ ${ }^{3}$ Professor, Department of Nursing, Hanyang University, 222 Wangsimni-ro, \\ Seongdong-gu, Seoul, 133-791, Korea \\ *Corresponding Author: Tae Kyung Kim \\ 54, Yanggi-ro, Busanjin-gu, Busan 614-715, Korea. \\ E-mailphoebetk@hanmail.net
}

\begin{abstract}
This study is a descriptive correlation study to determine the factors that affect immigrant women depression. In this study, migrant known factors on the impact of depression on women on the basis of previous studies acculturation stress, family stress, marital satisfaction, life satisfaction by focusing on variables such as the impact on immigrant women depression and depression check the effects of factors previously mentioned, and to provide a basis for early detection of depression and the prevention of immigrant women. The participants were 665 immigrant women who married Korean men. Data collection for this study was conducted between February to June 2010. Data collection methods to meet immigrant women in Seoul, Gyeonggi (Hanam, Yongin), Gyeongsangnam-do (Jinju), and migrant women who are based in Busan Center, Health Center, etc., were chosen as the place of data collection. The major findings were as follows; 1) Depression is generally characteristic of the separation group and was significantly higher than the married group in marital status $(F=5.063, p=.001)$. In in areas like "my husband's educational level" $(F=3.522, p=.007)$, "the religion of subjects" ( $F=3.200, p=.002)$, "husband religion" $(F=2.562, p=.013)$, and "family monthly income" ( $F=4.421, p=0.005)$, there was a statistically significant difference. 2) Immigrant women's depression and marital satisfaction $(r=-.112, p<.01)$, Korean life satisfaction ( $r=-.124, p<.01)$, than was the inverse correlation is significant and acculturation stress ( $r=.231, p<.01)$ were significantly correlated net. 3) Depression was predictive, the regression model of migrant women appeared to be significant $(F=$ $10.12, p<.001)$, indicating a revised explanatory power of the model coefficient of determination (Adj R2) was 0.17 with $17 \%$ explanatory power. Based upon the findings, this study provides useful information that could assist in reducing depression among married immigrant women and indicates that depression prevention programs are needed.
\end{abstract}

Keywords: Immigrant women, depression, acculturation stress, family stress, life satisfaction

\section{Introduction}

Due to globalization and neoliberal economic system, modern society has caused an increase in foreign workers, migrants, and quantitative induced increase in international migration through international marriage. 
South Korea has also in the last 10 years due to the influx of new social phenomena, and a multicultural multiethnic society of people-to-people exchanges between the two countries has been accelerating.

A particular problem in society now is the low birth rate. Reduced due to an aging workforce, there has been a shortage in the domestic economy and job creation. To resolve this, there was a program started in the 1990s called "Marriage Project for Rural Bachelor Movement", wherein marriage was used as a national instrument to improve these conditions. In this program, male and female immigrants were able to enter and stay in Korea, increasing the population by $3 \%$ to $1,576,034$. Married immigrants made up $13 \%$ of the population, with 150,865 people entering the multi-cultural environment [1]. Although this phenomena isn't really new, since capitalism was established in the $20^{\text {th }}$ century, the "feminization of migration" has become a phenomenon.

As women's poverty began to accelerate as a global trend, labor migration from other regions across the border became more frequent. Two weeks into their stay, these foreigners marry in order to stay permanently rather than temporarily.

Men who do not marry in demand in rural areas increased, which facilitated the change in perceptions and attitudes toward marriage according to the information globalization, neighbors, etc. to recognize women that try to escape poverty in Korea. Women who try to marry two weeks into their temporary stay in Korea to be able to stay permanently also increased. As a result, family culture has also started changing with the introduction of women with differing cultural backgrounds into Korean families.

Looking at the 2011 marriage statistics in Korea, women account for the majority of all married immigrants at $98.4 \%$. With women from developing countries such as China (45.2\%), Vietnam (28.8\%), the Philippines (6.5\%), and Cambodia (3.4\%), mainly third world women are at the center [1]. Korean society still has a different social and cultural background, and in accepting foreigners and especially exclusive rights for women in Southeast Asia, a vast majority of marriages with unfriendly attitudes have become prevalent. This is because women's poverty and the low socioeconomic status in these countries did not properly educate the population as they entered the Korean society for economic reasons rather than to become a family. Because of this, social distrust has formed. [2].

Because of this attitude, migrant women are experiencing divorce or are subject to prejudice and discrimination, and even suffer domestic violence. In fact, according to data by the National Statistical Office, there has been an increase in Korean men and foreign women being divorced in 2009. With the number of cases of marriage at 11,692, only one year more than 1255 cases, 437 cases $(3.9 \%)$ corresponds to $9.4 \%$ of the total divorces.

In particular, the international migrant women are living in Korea, so they must adjust the social and cultural ideals. However, their linguistic and psychological adjustment states are not prepared specifically for Korean society, and this is causing various problems.

According to doctors, the domestic difficulties of migrant women, such as unfamiliarity to the environment they immigrated to and communicating in marriage, result from the stressful process of adapting to a new culture, dealing with in-laws and conflict with her husband, and child problems. This can also result from personality problems like habitual beatings and violence, routine abuse, and human rights violations, including domestic labor.

Migrant women experience stress and a variety of difficulties which exert a great influence on their families and communities, therefore, research on their depression and mental health, such as anxiety can be very important.

Depressed people do not have hope for the future, and they feel that the future is pointless to see. They also feel worthless to the outside world, and mostly see the future in a negative perspective. Throughout the pre-Depression generation of life in modern society, all psychological experiences are very common (Seligman). Depression is a very 
common disease that can occur in one out of five people in a population of about 340 million people. Approximately $8 \%$ of 320 million people in Korea are suffering from depression each year.

If the lifetime prevalence of major depressive disorder is $10-25 \%$ in women, men have been reported in 5-12\%, which shows that occurrence in women is twice as high compared to men [3]. 30-40\% of people experience depression at least once in a lifetime, and a person is experiences a degree of depression once or twice during all life periods. A particularly large number of women was also reported to experience depression [4]. The Health Insurance Review and Assessment Service is a result of analyzing the medical personnel of depression from 2005 to 2009. 435,000 people showed up who was on call, and the number of patients increased by $16.8 \%$ to 508,000 people in four years. Looking into the gender of males in the population of 35 million people, 15 13,000 female patients as compared to 4,000 men, there appears to be much more than doubled.

In general, married immigrant women have to adapt a process that should help them start a new life in another culture. This can cause high intensity stress and depression in any individual, especially when it exceeds the coping capacity of the individual to cultural change, which can result in serious mental health problems such as anxiety. As the presence of married immigrant women who need to adapt suddenly to Korean society has increased, they may experience a crisis on dangerous mental health during this adaptation process. Therefore, it is important to look for ways to reduce psychological difficulties such as anxiety and depression to a minimum in married immigrant women. These women are presented as a matter of major depressive mental health [5].

If married immigrant women, who already have this mental illness in the course of incidence, have to adapt to different cultures that are more difficult to adapt to, they may undergo double the stress.

Because of this, depression is triggered; therefore, it is necessary to think about ways to prevent a serious impact on the adaptation of married immigrant women.

Since a woman's depression can exacerbate a parent and child relationship and result in marital conflict and discord, it has also been pointed out as a cause of marital relationship dissatisfaction. Depression and the mental health status of migrant women, especially married immigrant women, is a serious situation, but the mental health treatment utilization of these appear very low.

Thus, there is a need for effective support for the independence and social adaptation of immigrants and the time required for actively providing social integration services to enhance the acceptance of our multicultural society

Research on migrant women as well as women's depression show a high degree of depression compared to its own nationals [6]. Marital relationship or children's issues, despite having a number of mental health problems, showed a negative attitude in management consulting organizations use and treatment of the situation is urgent for them.

In marriages and relationships, some of the factors that affected depressed women were acculturation stress [5], marital satisfaction [6], couple and family stress and life satisfaction, marital period [7, 8], and economic status [9].

However, most of the research studies are targeted to other areas, and the study of immigrant women in the country are lacking.

In this study, the known factors on the depression of migrant women on the basis of previous studies are acculturation stress, family stress, marital satisfaction, life satisfaction by focusing on variables such as the impact on immigrant women Depression and Depression check the effects of factors, and to provide a basis for early detection of depression and the prevention of depression in immigrant women. 


\section{Method}

\subsection{Research Outline}

This study is a descriptive study using self-expression causal Questionnaire survey that reported attempts to identify the factors of depression and its impact on immigrant women.

\subsection{Participants}

The subjects were married Korean men and women who immigrated to Korea. The subjects agreed in writing to participate in the research and extraction amenities. The female subjects were women who can read and answer the questionnaire produced in the language of each country.

The sample size is $G^{*}$ Power to the sample size for the regression analysis program with a 3.0 statistical power $(1-\beta) .80$, the significance level $(\alpha)=.05$, effect size (f2) when calculated based on the 0.15 the sample size was 197 recommendations. In this study, the sample size was met by 665 people.

\subsection{Data Collection Method and Ethical Consideration}

The participants were 665 immigrant women who married Korean men, selected after getting an approval from Research Ethics Committee (HYI-12-031-3) of ' $\mathrm{H}$ ' University.

Data collection for this study was conducted between February to June 2010. Data collection methods were to meet immigrant women in Seoul, Gyeonggi (Hanam, Yongin), Gyeongsangnam-do (Jinju), and migrant women who are based in Busan Center, Health Center, etc. were chosen as the place of data collection.

Researchers and research assistants visited each institution directly for data collection to explain the purpose and intent of the chief engineer for the study, and consent for the data collection was obtained after the immigrant women who visit the place was placed under the coordination of each director.

Applicants study the manner, and for the purposes of research assistants who wish to participate in research, the study of risk and reward, were described anonymously for the content of research, research that person is fully in accordance with the autonomous decision to discontinue study participation. Description and data were collected through a structured questionnaire under the research agreement.

\subsection{Research Tools}

2.4.1. Depression: In this study, the South Korea depression test (KDS) was used to measure the depression of the subjects. This tool is in the cognitive domain of negative thoughts about the future ( 5 items), negative thoughts about the self ( 5 items), emotional area of worry and anxiousness (5 items), depressed mood (5 items), and physical domain of somatic symptoms (5 questions). It also consists of a loss (5 items) of real areas of motivation, and were rated from 0 to 5 points on a Likert type scale with higher scores, with 4 points meaning that depression is high. Reliability at the time of development was measured using Chronbach's a $=.85$, was Chronbach's a $=.84$ in this study.

2.4.2. Marital Satisfaction: To measure the marital satisfaction of the subjects in this study, the Olson, Fournier, \& Druckman (1982) of the ENRICH (Enriching \& Nurturingg Relationship Issues, Communication \& Happiness) scale was used. This tool consists of 10 items Tone, each item has a higher score, where 5 points in 1 point to 5-point scale of Likert type means that marital satisfaction is high. The reliability of the tool was developed at the time Chronbach's a $=.90$, it was Chronbach's a $=.94$ in the present study. 
2.4.3. Korean Life Satisfaction: Life satisfaction of the subjects in this study by Lehman, et al., (1982) and Life Satisfaction (Life Satisfaction Scale) by modifying the complement back eunryeong (2003) tool was created by reorganizing into eight areas for foreigners to meet the measure of life satisfaction was used. Life satisfaction tool is the living environment satisfaction, conscious economic satisfaction, friends and relationships, physical and mental health, vocational and day, jaahgam, and divided into general life satisfaction, jimyeo higher the score with 5 points Likert type scale of life satisfaction It means high. The reliability of the tool was developed at the time Chronbach's a $=.82$, it was Chronbach's a $=.91$ in the present study.

To measure the family stress of the subjects in this study, McCubbin's (1981) FILE (Family Inventory of Life Events and Changes) scale was used as a complementary tool to the center of the 18-item modified. Sub-areas of family stress, family (4 items), economic issues (4 items), Vocational and family conflict (4 items), interpersonal (4 items), was composed of health and integrity ( 2 items) of Likert type from one point to five-point scale, with higher scores, five points means a higher degree Les Ste family. Reliability at the time of development was measured using Chronbach's a $=.87$, was Chronbach's a $=.95$ in this study.

2.4.5. Acculturation Stress: In this study, participants were measured for the stress of acculturation according to Hover \& King (1996) of social, attitudinal, familial, environmental, cultural adaptation Stress Scale (Social Attitudinal Familial, and Environmental Acculturative Stress Scale for Children: The SAFE) to a total of 10 items was higher by 4 points scored from 0 to 5 points in a Likert scale format, which means that acculturation stress is high. Reliability at the time of development was measured using Chronbach's $\mathrm{a}=.89$, was tool Chronbach's $\mathrm{a}=.90$ in this study.

\subsection{Data Analysis}

The collected data is generally characteristic of the subjects. It was accidental and percentages using SPSS Window 15.0 program, the depression according to the characteristics of subjects were analyzed by ANOVA and t-test, ANOVA and mean comparison analysis was post hoc analysis Sheffe. The relationship between the main variables were analyzed using the Pearson

To investigate the impact of depression on immigrant women, data were analyzed using stepwise multiple. A correlation coefficient in the correlation between the variables used in the analysis were shown to be less than a factor of 0.8; each of these factors was analyzed using an input (Enter) method. Test results in the depressed dependent variable in the regression analysis showed that for a home that meets all of the conditions.

\section{Result}

\subsection{Differences in Depression According to General Characteristics}

The results of comparing the degree of depression and its general characteristic of the subjects are shown in Table 1.

The average age of study subjects are as follows: the most common is 29.84 years old, $34.7 \%$ are $26-30$ years old or younger, while under the category "when I came to Korea", the average age was 25.97 years old, with the most common vertical $20-2975.8 \%$.

Under the category "my husband's age" is $40-49$ years old, average 41.83 years old and $55.0 \%$ in the most common nationality of the owner is found to be $86.4 \%$, its nationality.

The most common country of origin is Vietnam $53.3 \%$, period of stay in Korea was the highest in more than three years is $35.9 \%$. 
Marital status is married and her husband was the most common subjects of education. In religion, $81.2 \%$ of Shamanism is the most frequent were respectively $47.2 \%$ and the husband of religious subjects is as high school graduates, $41.2 \%$ and $55.5 \%$ respectively, with $51.4 \%$ the most common.

The average monthly income of a family is ten thousand won to $234.62 \%, 100-200$ thousand won. The husband was most common in $48.4 \%$ subjects had a $95.3 \%$ have a job is $62.4 \%$ showed no job. Korean proficiency of the subjects showed an average of 2.88 points.

Depression is generally characteristic of the separation group, and this was significantly higher than the married group in marital status $(\mathrm{F}=5.063, \mathrm{p}=.001)$. My husband educational level $(\mathrm{F}=3.522, \mathrm{p}=.007)$, the religion of subjects $(\mathrm{F}=3.200, \mathrm{p}=$ $.002)$, husband religion $(\mathrm{F}=2.562, \mathrm{p}=.013)$, family monthly income $(\mathrm{F}=4.421, \mathrm{p}=$ $0.005)$, there was a statistically significant difference.

\section{Table 1. Depression by Demographics and General Characteristics of Participants ( $\mathrm{N}=665)$}

\begin{tabular}{|c|c|c|c|c|c|c|c|}
\hline Characteristics & Category & $\mathrm{n}$ & $\%$ & Mean(SD) & $\mathrm{t}$ ot $\mathrm{F}$ & $p$ & Scheffe \\
\hline \multirow[t]{6}{*}{ Age(yr) } & $\geq 25$ & 192 & 29.4 & $1.82 \pm .55$ & \multirow{6}{*}{.870} & \multirow{6}{*}{.481} & \\
\hline & $26-30$ & 226 & 34.7 & $1.77 \pm .54$ & & & \\
\hline & $31-35$ & 121 & 18.6 & $1.74 \pm .50$ & & & \\
\hline & $36-40$ & 73 & 11.2 & $1.84 \pm .59$ & & & \\
\hline & $41 \leq$ & 40 & 6.1 & $1.87 \pm .58$ & & & \\
\hline & \multicolumn{4}{|c|}{$\mathrm{M}(\mathrm{SD})=29.84 \pm 6.59$} & & & \\
\hline \multirow{5}{*}{$\begin{array}{l}\text { When I came of } \\
\text { age in Korea }\end{array}$} & $\geq 19$ & 27 & 4.3 & $1.78 \pm .59$ & \multirow{5}{*}{1.534} & \multirow{5}{*}{.205} & \\
\hline & $20-29$ & 486 & 75.8 & $1.78 \pm .53$ & & & \\
\hline & $30-39$ & 102 & 16.3 & $1.79 \pm .56$ & & & \\
\hline & $40 \leq$ & 19 & 3.5 & $2.05 \pm .67$ & & & \\
\hline & \multicolumn{4}{|c|}{$\mathrm{M}(\mathrm{SD})=25.97 \pm 5.79$} & & & \\
\hline \multirow{5}{*}{ Husband age } & $\geq 29$ & 14 & 2.1 & $1.87 \pm .57$ & \multirow{5}{*}{.182} & \multirow{5}{*}{.909} & \\
\hline & $30-39$ & 203 & 32.5 & $1.78 \pm .50$ & & & \\
\hline & $40-49$ & 347 & 55.0 & $1.80 \pm .57$ & & & \\
\hline & $50 \leq$ & 57 & 10.2 & $1.78 \pm .52$ & & & \\
\hline & $\mathrm{M}(\mathrm{SD})=41.83 \pm 6$ & .50 & & & & & \\
\hline \multirow[t]{2}{*}{ Nationality } & South Korea & 78 & 12.7 & $1.79 \pm .53$ & \multirow{2}{*}{-.185} & \multirow{2}{*}{.854} & \\
\hline & Its nationality & 540 & 86.4 & $1.80 \pm .54$ & & & \\
\hline \multirow{4}{*}{ Country of origin } & China & 234 & 36.6 & $1.84 \pm .57$ & \multirow{4}{*}{1.082} & \multirow{4}{*}{.356} & \\
\hline & Vietnam & 341 & 53.3 & $1.77 \pm .54$ & & & \\
\hline & Philippines & 34 & 5.3 & $1.92 \pm .38$ & & & \\
\hline & $\begin{array}{l}\text { Cambodia, } \\
\text { Mongolia, } \\
\text { Other }\end{array}$ & 31 & 4.8 & $1.78 \pm .52$ & & & \\
\hline \multirow{3}{*}{$\begin{array}{l}\text { In Korea } \\
\text { stay duration }\end{array}$} & Up to one year & 95 & 15.6 & $1.79 \pm .54$ & \multirow{3}{*}{.087} & \multirow{3}{*}{.967} & \\
\hline & $\begin{array}{l}\text { More than three } \\
\text { years }\end{array}$ & 218 & 35.9 & $1.82 \pm .54$ & & & \\
\hline & $\begin{array}{l}\text { Less than five } \\
\text { years }\end{array}$ & 152 & 25.8 & $1.80 \pm .60$ & & & \\
\hline
\end{tabular}




\begin{tabular}{|c|c|c|c|c|c|c|c|}
\hline & Over five years & 138 & 22.7 & $1.79 \pm .48$ & & & \\
\hline \multirow{5}{*}{ Marital Status } & Marriage $^{a}$ & 498 & 81.2 & $1.76 \pm .51$ & \multirow{5}{*}{5.063} & \multirow{5}{*}{.001} & \multirow{5}{*}{$a, b$} \\
\hline & Separation ${ }^{b}$ & 23 & 3.7 & $2.20 \pm .61$ & & & \\
\hline & Divorce $^{c}$ & 15 & 2.5 & $1.94 \pm .56$ & & & \\
\hline & Attached ${ }^{d}$ & 62 & 10.4 & $1.88 \pm .57$ & & & \\
\hline & $\begin{array}{l}\text { Widowed, } \\
\text { Other }{ }^{\text {e }}\end{array}$ & 14 & 2.2 & $1.96 \pm .72$ & & & \\
\hline \multirow{6}{*}{ Education Level } & None & 3 & 0.5 & $1.49 \pm .42$ & \multirow{6}{*}{1.241} & \multirow{6}{*}{.288} & \\
\hline & Elementary & 38 & 5.8 & $1.77 \pm .46$ & & & \\
\hline & Middle school & 223 & 33.9 & $1.75 \pm .57$ & & & \\
\hline & High school & 271 & 41.2 & $1.80 \pm .53$ & & & \\
\hline & College & 103 & 15.7 & $1.88 \pm .55$ & & & \\
\hline & Other & 20 & 3.0 & $1.90 \pm .45$ & & & \\
\hline \multirow{5}{*}{$\begin{array}{l}\text { Husband } \\
\text { education level }\end{array}$} & Elementary & 18 & 2.8 & $1.94 \pm .48$ & \multirow{5}{*}{3.522} & \multirow{5}{*}{.007} & \multirow{13}{*}{$\mathrm{d}, \mathrm{e}$} \\
\hline & Middle school & 92 & 14.5 & $1.84 \pm .51$ & & & \\
\hline & High school & 353 & 55.5 & $1.72 \pm .50$ & & & \\
\hline & College & 154 & 24.2 & $1.88 \pm .60$ & & & \\
\hline & Other & 19 & 3.0 & $1.97 \pm .65$ & & & \\
\hline \multirow[t]{8}{*}{ Religion } & None $^{a}$ & 306 & 47.2 & $1.83 \pm .51$ & \multirow{8}{*}{3.200} & \multirow{8}{*}{.002} & \\
\hline & Christianity $^{\mathrm{b}}$ & 95 & 14.7 & $1.74 \pm .57$ & & & \\
\hline & Catholic $^{c}$ & 36 & 5.6 & $1.84 \pm .40$ & & & \\
\hline & Buddhism $^{\mathrm{d}}$ & 169 & 26.1 & $1.72 \pm .56$ & & & \\
\hline & Swami ${ }^{\mathrm{e}}$ & 7 & 1.1 & $2.50 \pm .56$ & & & \\
\hline & Islam $^{f}$ & 10 & 1.5 & $1.85 \pm .47$ & & & \\
\hline & $\begin{array}{l}\text { Unification } \\
\text { Church }^{\mathrm{h}}\end{array}$ & $\begin{array}{l}13 \\
12\end{array}$ & 2.0 & $1.77 \pm .39$ & & & \\
\hline & Other & & 1.9 & $2.14 \pm .93$ & & & \\
\hline \multirow[t]{8}{*}{ Husband religion } & None & 332 & 51.4 & $1.83 \pm .54$ & \multirow{8}{*}{2.562} & \multirow{8}{*}{.013} & \\
\hline & Christianity & 105 & 16.3 & $1.77 \pm .56$ & & & \\
\hline & Catholic & 36 & 5.6 & $1.73 \pm .46$ & & & \\
\hline & Buddhism & 141 & 21.8 & $1.70 \pm .49$ & & & \\
\hline & Swami & 9 & 1.4 & $1.90 \pm .80$ & & & \\
\hline & Islam & 4 & 0.6 & $1.93 \pm .38$ & & & \\
\hline & $\begin{array}{l}\text { Unification } \\
\text { Church }\end{array}$ & 12 & 2.9 & $1.82 \pm .40$ & & & \\
\hline & Other & 7 & 1.1 & $2.48 \pm .96$ & & & \\
\hline \multirow{5}{*}{$\begin{array}{l}\text { Family monthly } \\
\text { income }(10,000 \\
\text { won) }\end{array}$} & $<100^{a}$ & 27 & 8.6 & $2.02 \pm .67$ & \multirow{5}{*}{4.421} & \multirow{5}{*}{.005} & \\
\hline & $101-200$ & 152 & 48.4 & $1.85 \pm .52$ & & & \\
\hline & $201-300^{c}$ & 96 & 30.6 & $1.70 \pm .47$ & & & $\mathrm{a}, \mathrm{c}$ \\
\hline & $>301^{\mathrm{d}}$ & 39 & 12.4 & $1.68 \pm .37$ & & & \\
\hline & $\mathrm{M}(\mathrm{SD})=234.62 \pm$ & 139.23 & & & & & \\
\hline \multirow[t]{2}{*}{ Job of husband } & Yes & 507 & 95.3 & $1.78 \pm .53$ & \multirow{2}{*}{1.404} & \multirow{2}{*}{.161} & \\
\hline & No & 25 & 4.7 & $1.94 \pm .60$ & & & \\
\hline Job & Yes & 215 & 37.6 & $1.82 \pm .56$ & -.857 & .392 & \\
\hline
\end{tabular}




\begin{tabular}{lllllll} 
& No & 357 & 62.4 & $1.78 \pm .51$ & & \\
Korean level & Very Low & 70 & 10.6 & $1.83 \pm .55$ & & \\
& Little low & 156 & 23.6 & $1.84 \pm .55$ & & \\
& Average & 271 & 41.0 & $1.81 \pm .53$ & 1.890 & .110 \\
& Little done & 112 & 16.9 & $1.67 \pm .51$ & & \\
& Well done & 52 & 7.9 & $1.86 \pm .63$ & & \\
& $\mathrm{M}(\mathrm{SD})=2.88 \pm 1.06$ & & & \\
\hline
\end{tabular}

\subsection{Marriages Degree of Depression and Associated Factors in Women}

Marriages in the degree of depression and depression-related factors in marital satisfaction among women is 1.80 points 3.50 points was related factors, Korea Life satisfaction 3.49 points, 3.69 points family stress, acculturation stress was 2.50 points.

Table 2. Mean and Standard Deviation of Variables

\begin{tabular}{llc}
\hline & \multicolumn{1}{c}{ Variables } & Mean(SD) \\
\hline Dependent variable & Depression & $1.80 \pm .54$ \\
& & \\
Independent variables & Marital satisfaction & $3.50 \pm .90$ \\
& & \\
& Korea Life Satisfaction & $3.49 \pm .68$ \\
& Family stress & $3.69 \pm 1.00$ \\
& Acculturation stress & $2.50 \pm .74$ \\
\hline
\end{tabular}

\subsection{The Correlation between Immigrant Women Depression and the Main Factors}

Immigrant women's depression and marital satisfaction $(r=-.112, p<.01)$, Korean Life satisfaction $(r=-.124, p<.01)$, than was the inverse correlation is significant and acculturation stress $(\mathrm{r}=.231, \mathrm{p}<.01)$ were significantly correlated net.

Korean Life satisfaction and marital satisfaction $(r=.536, \mathrm{p}<.01)$ and a significant net acculturation stress were correlated $(r=-.244, \mathrm{p}<.01)$ and had a significant inverse correlation.

South Korea stressful family life satisfaction $(\mathrm{r}=-.119, \mathrm{p}<.01)$ and acculturation stress $(\mathrm{r}=-.265, \mathrm{p}<.01)$ and had a significant inverse correlation (Table 3$)$.

Table 3. Correlation among Variables

\begin{tabular}{|c|c|c|c|c|c|}
\hline & $\mathrm{X}_{1}$ & $\mathrm{X}_{2}$ & $\mathrm{X}_{3}$ & $\mathrm{X}_{4}$ & $\mathrm{X}_{5}$ \\
\hline $\mathrm{X}_{1}$ & 1 & & & & \\
\hline $\mathrm{X}_{2}$ & $-.112^{\dagger}$ & 1 & & & \\
\hline$X_{3}$ & $-.124^{\dagger}$ & $.536^{\dagger}$ & 1 & & \\
\hline $\mathrm{X}_{4}$ & .058 & .033 & $-.119^{\dagger}$ & 1 & \\
\hline $\mathrm{X}_{5}$ & $.231^{\dagger}$ & $-.244^{\dagger}$ & $-.265^{\dagger}$ & .027 & 1 \\
\hline
\end{tabular}

\subsection{Factors Influencing on Immigrant Women Depression}

In order to determine the significant factors of depression in marital satisfaction, relevant factors like Korean life satisfaction, family stress, marital status between acculturation stress and general characteristics of the subjects like the husband's educaiton level, religion, family monthly income showed that there was a significant 
difference in depression. Multiple regression analysis based on these factors is the same as Table 4.

Depression was predictive regression model of migrant women appeared to be significant $(\mathrm{F}=10.12, \mathrm{p}<.001)$, indicating a revised explanatory power of the model coefficient of determination (Adj R2) was 0.17 with $17 \%$ explanatory power. Gyeonghon two weeks the main factors affecting depression in women, acculturation stress $(\beta=.17)$, her husband's religion $(\beta=-.11)$, family economic status $(\beta=-.13)$, the couple satisfaction $(\beta=0.17)$ was found in order, from the cultural adaptation stress has been identified as the most important predictors of depression in immigrant women.

Table 4 Factors Influencing on Immigrant Women Depression

\begin{tabular}{lcccccccc}
\hline \multicolumn{1}{c}{ Variables } & $\mathrm{B}$ & $\mathrm{S} . \mathrm{E}$ & $\beta$ & $\mathrm{t}$ & $p$ & $\operatorname{Adj}^{2}$ & $\mathrm{~F}$ & $p$ \\
\hline Constant & 2.179 & .20 & & 10.88 & .000 & & & \\
$\begin{array}{l}\text { Marital } \\
\text { satisfaction }\end{array}$ & -0.11 & .04 & -0.17 & -2.87 & .004 & .17 & 10.12 & $<.001$ \\
$\begin{array}{l}\text { Acculturation } \\
\text { stress }\end{array}$ & 0.11 & .04 & 0.17 & 2.80 & .005 & & \\
$\begin{array}{l}\text { Family economic } \\
\text { level }\end{array}$ & -0.08 & .04 & -0.13 & -2.30 & .023 & & \\
husband's religion & -0.4 & .02 & -0.11 & -1.99 & .048 & & & \\
\hline
\end{tabular}

Adj $R^{2}=$ Adjusted $R^{2}$

\section{Discussions}

This study on marital satisfaction targets migrant women living in Korea, using South Korean life satisfaction, family stress, acculturation stress and depression, and identifies variables by the above factors to determine the impact on future immigrant women depression. It has attempted to provide a basis for planning for the early detection and prevention programs.

In the present study, this separation came highly depressed than married population groups. These results indicated a strategy is needed to maintain a stable marital status, which appears to affect the marital status of a depressed migrant woman. In the depression, the husband's level of education was found to be lower when the depression of the migrant woman is higher, and the husband's level of education is higher when the depression of migrant women is lower, which is a result that matches the low level of depression-higher education in other studies [10].

The husband's religious view made a significant difference in depression scores of migrant women; religion is considered as a factor that may have more difficulty in the settlement process in South Korea living in other cases.

Therefore, the religious unity will be able to increase the stable settlement and satisfaction of migrant women.

In this study, marital status, husband's level of education, religion, religious husband, the depression according to the family monthly income showed that there was a significant difference.

Immigrant women on the subject's average age is 25.97 years old in Korea compared with an average of 41.83 Vertical migrant women and her husband shows that ,having a husband with a severe age difference which can be pointed out as a factor that aggravates the marital relationship.

Although age is not a factor affecting depression in other studies of immigrant women, age difference of spouses is considered necessary; it appears as a significant factor that is causing the problem of marital further research on this [11]. 
Stepwise multiple regression analysis to examine the impact acculturation stress factors on immigrant women's depression, her husband's religion, family economic status, marital satisfaction influences on depression explanatory power was found to be $17 \%$.

Acculturation stress in this study was one of the main predictors of depression. These is similar to results seen in previous studies and also satisfy this couple is also consistent with the result of factors affecting depression $[12,13]$.

Thus, the feed can be utilized for immigrant women on the basis of data on such factors by check to the depressed, targeting immigrant women and early detection of depression during program development to prevent and adapt cultural couple met.

\section{Conclusions}

This study is a descriptive correlation study to determine the factors that affect immigrant women depression. The results of this study showed that acculturation stress had the highest impact on depression. Therefore, early detection and prevention programs targeting depressed immigrant women will need to be prepared to form a variety of information and experience and ongoing relationships to help lower the Korea Culture and acculturation stress.

In addition, there is a need to develop a program to keep immigrant women and relationships according to her husband's religion and education, to maintain the marriage after marriage because it requires ongoing management of migrant women. Because of this the prevention and settlement of stable life and depression is required to increase the quality of life.

\section{Acknowledgements}

This study was funded by the National Research Foundation of Korea (NRF2012R1A1A3015474).

\section{References}

[1] "Staatistics Korea", Immigrant status 2013, Retrived, (2014) March, from http://www.index.go.kr/egans/sts.jsp/potal/sts/PO_STTS_IdxMain.jsp_cd=2430\&bbs=INDX_001.

[2] H. Fenta, I. Hyman and S. Noh, "Determinants of depression among Ethiopian immigrants and refugees in Toronto", The Journal of Nervous and Menatal Disease, vol. 192, (2004), pp. 363-372.

[3] E. S. Jung, E. K. Yoo and H. J. Kim, "Life experience of Korean men who married immigrant women in Korea", Advanced Science and Technology Letters, vol. 96, (2015), pp. 95-98.

[4] Y. C. Huang and N. J. Mathers, "Postnatal depression and the experience of South Asian marriage migrant women in Taiwan: Survey and semi-structured interview study", International Journal of Nursing Studies, vol. 45, (2008), pp. 924-931.

[5] A. R. Kim, "The influence that the conflict between the husbands and his immigrant wives to the satisfaction level of marriage life", Unpublished master's thesis, Pyongtaek University, Gyeonggido, (2008).

[6] E. K. Yoo, T. K. Kim and H. J. Kim, "Depression in married immigrant women in Korea", Advanced Science and Technology Letters, vol. 104, (2015), pp. 134-137.

[7] J. W. Berry, "Stress perspectives on acculturation", in D. L. Sam \& J. W.Berry (eds.), The Cambridge handbook of acculturation psychology, New York, NY: Cambridge University Press, (2006), pp. 43-57.

[8] R. C. Capps, J. Bronte-Tinkew and A. Horowitz, "Acculturation and father engagement with infants among Chinese and Mexican-origin immigrant fathers", Fathering: A Journal of Theory, Research, \& Practice about Men as Fathers, vol. 8, no. 1, (2010), pp. 61-92.

[9] H. S. Kim, "Impacts of social support and life satisfaction on depression among international marriage migrant women in Daegu and Kyungpook area", Journal of Korean Academy of Psychiatric and Mental Health Nursing, vol. 20, (2011), pp. 188-198.

[10] M. T. Kim, H. R. Han, H. S. Shin, B. K. Kim and H. B. Lee, "Factors associated with depression experience of immigrant populations; A study of Korean immigrants", Archives of Psychiatric Nursing, vol. 19, (2005), pp. 217-225.

[11] B. K. Finch, R. Frank and W. A. Vega, "Acculturation and acculturation stress: A social epidemiological approach to Mexican migrant farm workers' health", International Migration Review, vol. 38, (2004), pp. 236-262. 
[12] H. S. Lim, "The impact of acculturative stress and perceived social support on depression of marriagebased immigrant women in Korea: An examination of moderating and mediating effects of social support", Korean Journal of Family Welfare, vol. 15, no. 2, (2010), pp. 27-45.

[13] C. J. Yeh, "Age, Acculuration, Cultural Adjustment, and MentalHealth Symptoms of Chinese, Korean, and Japanese Immigrant Youths", Cultural Diversity and Ethnic Minority Psychology, vol. 9, no. 1, (2003), pp. 34-48.

\section{Authors}

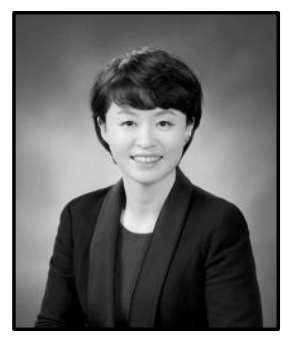

Tae Kyung Kim, RN, Ph.D. teaches Nursing at the School of Nursing, DongEui Institute of Technology located in Busan of South Korea. She began her career as a faculty of Women's Health Nursing in 2006 after receiving M.S.(1998) in Nursing from Hanyang University, and a Ph.D. in Nursing (2008) at the same university. Her main research interests include multicultural women's health and childbirth and Sanhujori.

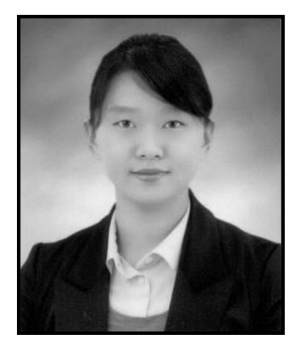

Hye Jin Kim, RN, Ph.D, teaches Nursing at the School of Nursing, Kyungbok University located in Gyeonggi. She began her career as a faculty of Women's Health Nursing in 2001 after receiving B.A. (1997) from Hanyang University, M.S. (2005)and a Ph.D.(2008) in Nursing from Hanyang University. She is coauthor of 'My mom health JUMP - Joy Ultra Mom Program' \& 'My mom health Sanhujori'. She participated in the study 'Development of program for the married immigrant women and family' \& 'Development of WISE HF Sanhujori Guideline'. Her main research interests include multicultural women's health and childbirth and Sanhujori, contraception.

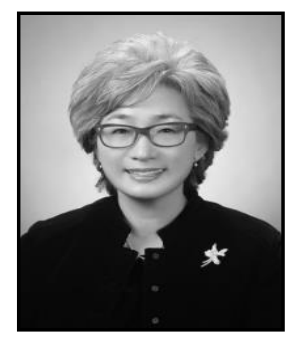

Eun Kwang Yoo, RN, Ph.D teaches Nursing at the School of Nursing, Hanyang University located in Seoul Korea. She began her career as a faculty of Women's Health Nursing in 1982 after receiving B.A. (1978) from Hanyang University, M.S.(1980) in Nursing from Yonsei University, and a Ph.D. in Nursing (1993) from University of California, San Francisco(UCSF) as a Fulbright Doctoral Grantee. She has been a Fulbright Visiting Scholar at Boston College, School of Nursing (2007 2008), a vice president of Korean Fulbright Alumni since 2004 and a Chair of Korean Sanhujori Academy since 1999. Professor Yoo, a leading authority on Women's health nursing, especially the pioneer of Sanhujori, Korean traditional postpartum care, and IPC (Integrated Postpartum Care), is the author of 'East meets West- Integrated postpartum care - Sanhujori \& nursing care' and 'Contemporary Sanhujori' and co-author of 24 books including 'My mom health JUMP - Joy Ultra Mom Program' \& 'My mom health Sanhujori' with many other articles. Her recent research interest is to develop a system for connection of health knowledge with consumer's everyday life. She was selected as a Marquis Who's Who in America (2013 Edition) and TOP 100 Health Professionals in America 2013. 
International Journal of $u-$ and e- Service, Science and Technology Vol.8, No. 10 (2015) 